\title{
ECONOMIA BRASILEIRA: UMA ANÁLISE DAS EXPORTAÇÕES DE AÇÚCAR
}

Ana Caroline Veiga

Universidade do Oeste Paulista - UNOESTE, Curso de Administração, Presidente Prudente , SP. Email: veiga.caroline@hotmail.com

\section{RESUMO}

A presente pesquisa vem relatar as relações no comércio exterior como um dos fatores que mais movimentam a economia brasileira. O setor sucroalcooleiro proporciona grande rentabilidade econômica ao país, pois além da sua produção, exporta grande quantidade do açúcar para diversos países. Esta pesquisa analisa o papel exportações para o crescimento econômico do país sendo possível, relacionar ao comércio exterior, voltado ao setor sucroalcooleiro a fim de identificar a maneira como as relações internacionais são fatores determinantes na economia brasileira a fim de definir qual a importância da importação e exportação para a economia brasileira, identificando assim, como as transações no mercado externo podem influenciar a macroeconomia.

Palavras-chave: Economia. Exportação. Sucroalcooleiro.

\section{BRAZILIAN ECONOMY : AN ANALYSIS OF SUGAR EXPORTS}

\begin{abstract}
This research report has relations in foreign trade as one of the factors that drive the Brazilian economy. The sugar and ethanol industry provides great economic return to the country, as apart of its production, export large quantity of sugar in several countries. This research examines the role exports to economic growth is possible, relate to foreign trade, focused on the sugar and alcohol sector in order to identify how international relations are decisive factors in the Brazilian economy in order to define the importance of import and export to the Brazilian economy, thus identifying as transactions in foreign markets can affect the macroeconomy .
\end{abstract}

Keywords: Economy. Export. Sugarcane. 


\section{INTRODUÇÃO}

A economia brasileira, antes de ser reconhecida internacionalmente pelas exportações da grande variedade de produtos que possui, passou por várias fases de transição.

Atualmente o Brasil é líder mundial em exportações de soja, cana-de-açúcar, carne bovina, entre outros produtos ligados ao agronegócio. Além de um grande exportador de suas riquezas, o setor sucroalcooleiro proporciona grande rentabilidade econômica ao país, pois além de produzir açúcar e álcool, exporta grande quantidade do açúcar para diversos países.

As relações no comércio exterior é um dos fatores que mais movimentam a economia brasileira, pois possibilitam atender a demanda do seu mercado interno e comercializar o restante com seus parceiros ao redor do mundo.

Diante da flexibilização econômica que Brasil enfrenta, o objetivo desta pesquisa é analisar o cenário econômico relacionando-o com as atividades internacionais a fim de identificar a importância da mesma para o crescimento do país.

\section{METODOLOGIA}

A definição do método de pesquisa para a elaboração do projeto torna-se essencial para um bom andamento da pesquisa. Os aspectos metodológicos deste projeto foi pesquisa descritiva, estudo de caso e tem como instrumento de coleta de dados, a pesquisa bibliográfica com abordagem qualitativa.

Segundo Gil (2010, p. 27), "as pesquisas descritivas têm como objetivo a descrição das características de determinada população. Podem ser elaboradas também, com a finalidade de identificar possíveis relações entre variáveis", com o objetivo de descrever as ações do comércio exterior e do agronegócio comparando-o com o cenário macroeconômico atual.

Desta forma, proporcionando maior familiaridade a respeito do tema, sendo possível maior entendimento e visa proporcionar uma visão geral dos fatos determinados.

Segundo Gil (2010, p. 37), “o estudo de caso consiste no estudo profundo e exaustivo de um ou poucos objetos, de maneira que permita seu amplo e detalhado conhecimento, tarefa praticamente impossível mediante outros delineamentos já considerados." Com isso, foi possível compreender os processos das empresas exportadoras e preservar os dados para que não haja distorção da realidade, possibilitando assim, a compreensão do tema desenvolvido.

Para complementar o estudo, também foi utilizado pesquisa documental, que de acordo com Marconi e Lakatos (2005, p. 176) "é que a fonte da coleta de dados está restrita a documentos, escritos ou não, constituindo o que se denomina de fontes primárias", sendo 
possível a análise através de documentos já existentes, sendo eles ocorridos na atualidade ou já há algum tempo.

Ainda nesta pesquisa, foi utilizada a abordagem qualitativa que segundo Oliveira (1999 p. 116) "as pesquisas que se utilizam desta abordagem possuem a facilidade de poder descrever a complexidade de uma determinada hipótese ou problema e analisar a interação de certas variáveis compreendendo os processos analisados", sendo assim, será possível analisar os fatos apresentados de acordo com demais estudos já realizados, sendo possível o maior entendimento e análise acerca do assunto apresentado.

“A pesquisa bibliográfica é elaborada com base em material já publicado. Tradicionalmente, esta modalidade de pesquisa inclui material impresso, como livros, revistas, jornais, teses, dissertações e anais de eventos científicos" (GIL 2010, p. 29), definindo-se através de uma ampla e detalhada pesquisa, fundamentada em diversos autores a fim de proporcionar maior conhecimento do tema. Além da pesquisa em livros, revistas e outros materiais já citados, foram utilizados também como apoio, materiais publicados em sites.

\section{RESULTADOS}

A movimentação da economia brasileira é composta por diversas partes. Uma delas e também muito importante, são os produtos comercializados interna e externamente que compõem o agronegócio.

Através dos estudos realizados por Araújo (2010, p. 18) “o agronegócio brasileiro tem grande importância na balança comercial, participando com mais de $36 \%$ da pauta de exportações e sendo altamente superavitário, de modo a contribuir para evitar os déficits comerciais do Brasil".

A partir dos avanços tecnológicos que surgiram e a estabilização econômica a partir de 1990, o cultivo e produção ganharam forças e desde então o Brasil tornou-se o maior produtor de cana-de-açúcar e maior exportador de açúcar do mundo.

A cana de açúcar sendo a única matéria prima para a industrialização do açúcar e do álcool, segundo dados do MAPA (Ministério da Agricultura Pecuária e Abastecimento, online, 2014) faz com que o Brasil seja o primeiro em produção mundial do produto e o responsável pela exportação de mais da metade dele.

O comércio desenvolvido através das atividades do agronegócio refletem diretamente na situação econômica e financeira do Brasil uma vez que são destinadas ao comércio exterior: 
Tabela 1. Exportações Brasileiras do Complexo Sucroalcooleiro

\begin{tabular}{c|c|c|c|c|c|c}
\hline \multirow{2}{*}{ Ano } & \multicolumn{2}{|c|}{ Complexo Sucroalcooleiro } & \multicolumn{2}{c|}{ Variação (\%) } & \multicolumn{2}{c}{ Preço Médio } \\
\cline { 2 - 7 } & Mil US\$ & Toneladas & Valor & Quant. & US\$/t & Var. (\%) \\
\hline 2003 & 2.315 .932 & 13.675 .321 & - & - & 169 & - \\
\hline 2004 & 3.153 .412 & 17.782 .211 & $36,2 \%$ & $30,0 \%$ & 177 & $4,7 \%$ \\
\hline 2005 & 4.698 .891 & 20.320 .911 & $49,0 \%$ & $14,3 \%$ & 231 & $30,4 \%$ \\
\hline 2006 & 7.788 .106 & 21.666 .956 & $65,7 \%$ & $6,6 \%$ & 359 & $55,4 \%$ \\
\hline 2007 & 6.590 .131 & 22.207 .174 & $-15,4 \%$ & $2,5 \%$ & 297 & $-17,4 \%$ \\
\hline 2008 & 7.894 .239 & 23.632 .340 & $19,8 \%$ & $6,4 \%$ & 334 & $12,6 \%$ \\
\hline 2009 & 9.732 .909 & 27.018 .235 & $23,3 \%$ & $14,3 \%$ & 360 & $7,8 \%$ \\
\hline 2010 & 13.789 .920 & 29.582 .671 & $41,7 \%$ & $9,5 \%$ & 466 & $29,4 \%$ \\
\hline 2011 & 16.449 .769 & 26.960 .827 & $19,3 \%$ & $-8,9 \%$ & 610 & $30,9 \%$ \\
\hline 2012 & 15.044 .586 & 26.843 .453 & $-8,5 \%$ & $-0,4 \%$ & 560 & $-8,1 \%$ \\
\hline 2013 & 13.717 .911 & 29.483 .804 & $-8,8 \%$ & $9,8 \%$ & 465 & $-17,0 \%$ \\
\hline
\end{tabular}

Fonte: AgroSat Brasil, a partir de dados da SECEX/MDIC apud Ministério da Agricultura, Pecuária e Abastecimento

Segundo os dados fornecidos, o crescimento em todo o setor foi significativo desde 2003 até 2010 , resultando um aumento de aproximadamente $116 \%$. A queda nas exportações referente aos anos 2011 e 2012 nada mais é que reflexo da crise que atingiu o setor nos últimos anos.

Apesar do retorno do crescimento no ano de 2013 em relação ao ano de 2011 e 2012 ter sido parcialmente significativo, o setor ainda apresentava algumas quedas, pois a produção sofreu aumento somente de 0,33\% comparado a 2010.

Analisando individualmente o açúcar, pode-se constatar que o montante mais expressivo é do próprio, conforme mostra tabela abaixo:

Tabela 2. Exportações Brasileiras de Açúcar

\begin{tabular}{c|c|c|c|c|c|c}
\hline \multirow{2}{*}{ Ano } & \multicolumn{2}{|c|}{ Açúcar } & \multicolumn{2}{c|}{ Variação (\%) } & \multicolumn{2}{c}{ Preço Médio } \\
\cline { 2 - 7 } & Mil US\$ & Toneladas & Valor & Quant. & US\$/t & Var. (\%) \\
\hline 2003 & 2.140 .022 & 12.914 .410 & - & - & 166 & - \\
\hline 2004 & 2.640 .229 & 15.763 .929 & $23,4 \%$ & $22,1 \%$ & 167 & $1,1 \%$ \\
\hline 2005 & 3.918 .850 & 18.147 .062 & $48,4 \%$ & $15,1 \%$ & 216 & $28,9 \%$ \\
\hline 2006 & 6.167 .015 & 18.870 .167 & $57,4 \%$ & $4,0 \%$ & 327 & $51,3 \%$ \\
\hline 2007 & 5.100 .530 & 19.359 .021 & $-17,3 \%$ & $2,6 \%$ & 263 & $-19,4 \%$ \\
\hline 2008 & 5.483 .037 & 19.472 .520 & $7,5 \%$ & $0,6 \%$ & 282 & $6,9 \%$ \\
\hline 2009 & 8.377 .828 & 24.294 .098 & $52,8 \%$ & $24,8 \%$ & 345 & $22,5 \%$ \\
\hline 2010 & 12.761 .731 & 27.999 .859 & $52,3 \%$ & $15,3 \%$ & 456 & $32,2 \%$ \\
\hline 2011 & 14.941 .663 & 25.359 .150 & $17,1 \%$ & $-9,4 \%$ & 589 & $29,3 \%$ \\
\hline 2012 & 12.844 .869 & 24.342 .295 & $-14,0 \%$ & $-4,0 \%$ & 528 & $-10,4 \%$ \\
\hline 2013 & 11.842 .458 & 27.154 .304 & $-7,8 \%$ & $11,6 \%$ & 436 & $-17,4 \%$ \\
\hline
\end{tabular}

Fonte: AgroSat Brasil, a partir de dados da SECEX/MDIC apud Ministério da Agricultura, Pecuária e Abastecimento

Após a comparação dos dados apresentados, foi possível constatar que aproximadamente 90,08\% das exportações de todo o complexo sucroalcooleiro corresponde ao açúcar. Suas exportações tiveram o seu melhor momento entre o período de 2008 a 2010, onde houve 
crescimento em todos os anos. Isso faz com que além de ser um dos principais produtos na gama do agronegócio brasileiro, é também um dos primeiros no ranking de exportação, sendo que atualmente a produção de açúcar foi afetada devido à crise que assombra o setor. A queda do volume exportado prevaleceu nos anos de 2011 e 2012, resultando um total de 13,06\% comparado aos anos de 2010/2012. Em contrapartida, o crescimento retornou em 2013 na casa dos $11,6 \%$ quando comparado ao cenário de 2012 , entretanto, com o preço bem abaixo dos anos anteriores.

\section{DISCUSSÃO}

É sabido por todos que a economia brasileira passou por diversas fases até chegar na situação atual. Antes mesmo da estabilização econômica do Brasil e a abertura da economia para as relações internacionais, o país passou por vários períodos de crises; um deles, ainda durante a Segunda Guerra Mundial, onde o colapso era generalizado ao que se referia ao sistema financeiro.

Para auxiliar os países em crise foram criados o FMI e do BIRD, que conforme Furtado (2000) relata, entraram em ação em 1947 como intuito de apoiar os países integrantes ao que se diz respeito aos déficits da balança de pagamentos e a promoção do crescimento da economia dos países e regiões mais emergentes; porém, no período em que surgiram, não houve grande sucesso devido a forte crise que rodeava todo o mundo após a Guerra.

Com todos estes acontecimentos, as reservas financeiras do Brasil caíram drasticamente a ponto de não serem suficientes por um longo período além daquele atual. Deste modo, com o fim da guerra, a economia do país estava devastada, segundo Furtado $(2000$, p.171) "O declínio dos saldos da balança comercial, o aumento do déficit da conta de serviço e a queda do nível das reservas provocaram o primeiro grave desajuste do balanço de pagamentos, ainda no primeiro semestre de 1947". Neste período, o consumo de produtos importados ficou um pouco mais restrito, pois a prioridade de importação era daqueles que eram classificados como bens essenciais. Neste período pós-guerra, toda a economia brasileira estava com dificuldades e para combater os sérios desajustes econômicos, foi necessário que o governo solicitasse seu primeiro financiamento junto ao FMI.

Houve um período que a economia brasileira ficou estável, onde houve apoio às exportações e expansão do mercado internacional, porém a balança de pagamentos encontravase em constante instabilidade fazendo com que a dívida externa crescesse devido à facilidade da captação de recursos diante do mercado financeiro internacional. 
A economia voltou a chegar perto da estabilização somente a partir de 1990 com o governo de Fernando Collor de Melo, que tinha como principal objetivo fazer com que as crises anteriores fossem superadas. Collor então propôs uma reforma econômica partindo do princípio de estabelecer princípios para que o Brasil possuísse uma economia estável e que pudesse propiciar abertura às relações internacionais. Apesar do Plano Collor não ter obtido resultados totalmente satisfatórios em sua fase de implantação e execução, teve também, seu lado positivo. Collor propunha restrição às importações e total apoio às exportações e foi através delas que a balança comercial, já em 1991, passou a apresentar bons resultados.

O principal fator colaborativo para o desenvolvimento econômico foi o Plano Real, que também conhecido como programa de estabilização econômica, teve como principal objetivo, proporcionar abertura comercial do Brasil para os demais países, e a estabilização econômica foi sem duvida, o maior e principal marco para a mudança no país.

Com todas as medidas e planos para a redução da inflação e estabilização da economia, ainda faltavam recursos, pois o Brasil ainda sofria com a elevada dívida externa.

O Brasil ainda passava por algumas dificuldades no que se referia ao pagamento da dívida externa. Somente a partir de 2002, com o governo Lula, a situação econômica retomou e estabilizou seus superávits, que de acordo com Mariano (2012 p. 19):

A partir de 2004, ocorreu um quadro de melhoria no setor externo da economia brasileira, fato que contribuiu para que a questão da dívida fosse minimizada. Em 2006, aproveitando esse contexto favorável, o governo brasileiro antecipou a quitação da dívida junto ao FMI. Essa atitude, além do aspecto de natureza politica, gerou uma economia no que se refere ao pagamento de juros.

As mudanças que ocorreram no início do governo Lula fez com que a política fiscal e cambiária proporcionasse maior facilidade aos superávits. A melhor condição econômica do Brasil colaborou para que começasse a surgir meios de pagamento da dívida externa e foi a partir de 2004 que a economia brasileira passou a apresentar bons resultados. Conforme o gráfico abaixo é possível perceber o crescimento da economia no período do governo Lula: 
Gráfico 1. PIB Brasileiro - de 2003 a 2013

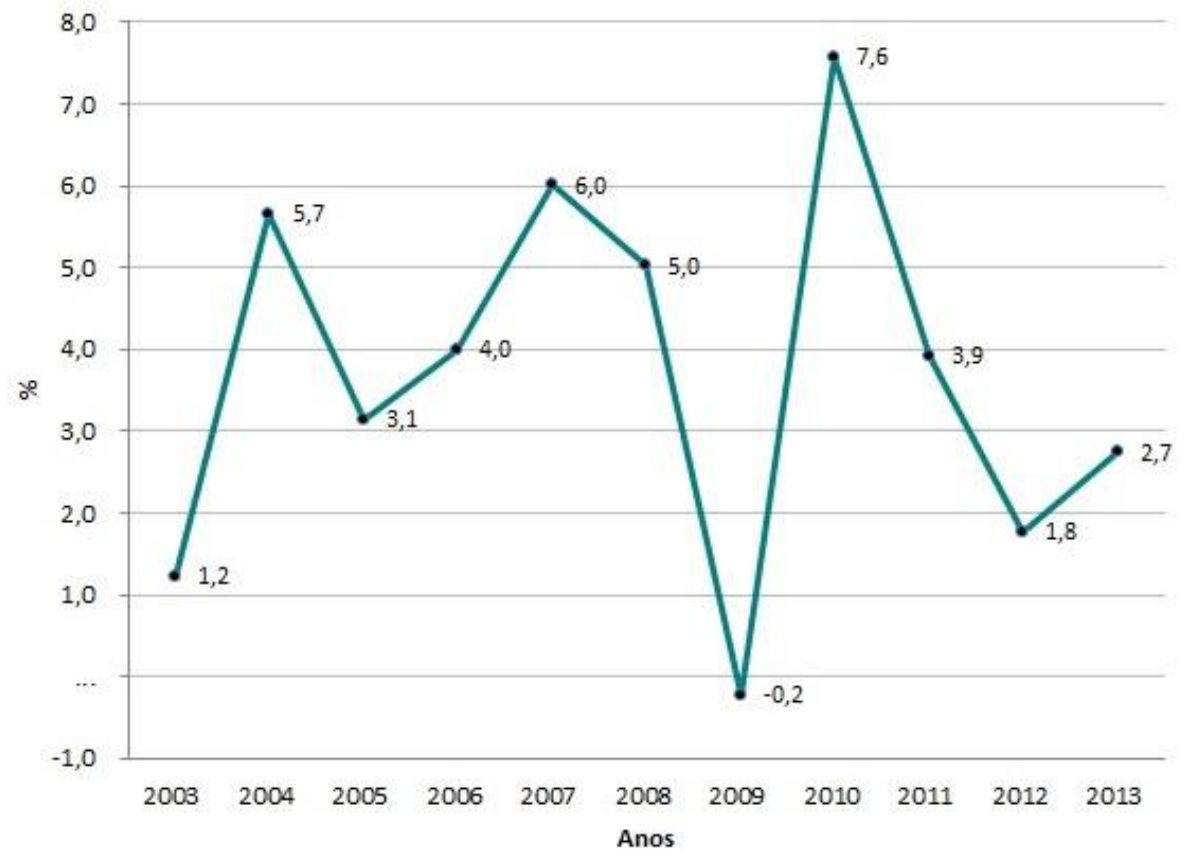

Fonte: IBGE apud Banco Central do Brasil

Ainda assim, não era possível dizer que o Brasil estava livre de crises; o crescimento do PIB foi apenas um fator importante para a iniciativa das demais melhorias.

Entretanto, em 2008 uma crise mundial afetou não só o Brasil, mas também muitos outros países. Surgindo nos Estados Unidos, fez com que o FMI alertasse as demais economias do mundo de que a perda poderia ser de trilhões de dólares. Em 2010, o país voltou a crescer e as perspectivas para os próximos anos também eram positivas, porém, com a mudança de governo, a situação econômica do Brasil voltou a ser instável. Atualmente, o Brasil passa por um colapso econômico, onde todo o país está sofrendo as consequências, desde desemprego até o aumento nos preços dos alimentos básicos e combustíveis.

A alta do dólar também é fator colaborativo para a elevação dos preços e do descontrole da inflação, sendo fator colaborativo para a instabilidade econômica.

\section{CONCLUSÃO}

A presente pesquisa visou relacionar o comércio internacional com a economia brasileira e demonstrar sua real importância. Os produtos comercializados pelo Brasil com algumas partes do mundo são provenientes da sua própria produção, que se tornou ampla e rica e, além disso, pôde proporcionar grande crescimento da economia e do setor sucroalcooleiro individualmente.

A atual situação do país não é das melhores, pois vem sofrendo reflexos desde a crise de 2009, que inicialmente não atingiu à ponto de abalar as estruturas econômicas do país; outro fato 
que tem contribuído para a instabilidade econômica sofrida nos últimos anos foi a troca do governo que devido o baixo crescimento e a da alta inflação ocasionaram novos déficits.

Conforme demonstrado durante a pesquisa, diversos setores da economia estão em fase de crise; o sucroalcooleiro está passando pela pior fase já enfrentada no país, porém, é um setor que está em constante crescimento, pois proporciona um grande leque de oportunidade de comercialização.

A pesquisa identificou que apesar da crise, a empresas tem feito o seu melhor para manter-se estável no mercado e para recuperar-se após ela. Pode-se dizer que são em momentos de crise em que mais existe crescimento e aprendizado.

Portanto, conclui-se que se o Brasil está mal economicamente, a tendência é que as empresas públicas e privadas acompanhem o seu ritmo. Sendo assim, o esforço das partes interessadas é fundamental para a administração de todos estes meios esteja sempre da melhor maneira para que não haja déficits na balança de pagamentos, proporcionando um melhor desempenho e apoio quanto às exportações.

\section{REFERÊNCIAS}

ARAUJO, M. J. Fundamentos de Agronegócios. 3 ed. São Paulo: Atlas, 2010.

BANCO CENTRAL DO BRASIL. In: Produto Interno Bruto. Disponível em: <www.bcb.gov.br/pec/Indeco/Port/ie1-51.xls>. Acesso em: 13 Mai. 2015.

FURTADO, M. B. Síntese da economia brasileira. 7 ed. Rio de Janeiro: LTC, 2000.

GIL, A. C. Como elaborar projetos de pesquisa. 5 ed. São Paulo, 2010.

MARCONI, M. A.; LAKATOS, E. M. Fundamentos de metodologia científica. 5 ed. São Paulo: Atlas, 2003.

MARIANO, J. Introdução à economia brasileira. 2 ed. São Paulo: Saraiva, 2012.

Ministério da Agricultura. Cana-de-açúcar. Disponível em: < http://www.agricultura.gov.br/vegetal/culturas/cana-de-acucar>. Acesso em: 04 Mai. 2015. 